\title{
Mechanics of Advanced Materials and Structures
}

\section{Vibroacoustic performance of fiber metal laminates with delamination}

\section{B. Balakrishnan, S. Raja, D. Dwarakanathan \& Amirtham Rajagopal}

To cite this article: B. Balakrishnan, S. Raja, D. Dwarakanathan \& Amirtham Rajagopal (2016) Vibroacoustic performance of fiber metal laminates with delamination, Mechanics of Advanced Materials and Structures, 23:12, 1369-1378, DOI: 10.1080/15376494.2015.1091523

To link to this article: https://doi.org/10.1080/15376494.2015.1091523

Accepted author version posted online: 25

Sep 2015.

Published online: 14 Apr 2016.

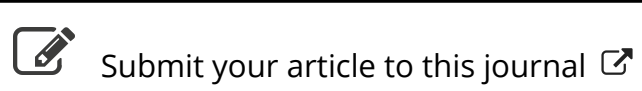

Џll Article views: 288

View Crossmark data \lceil 


\title{
Vibroacoustic performance of fiber metal laminates with delamination
}

\author{
B. Balakrishnan a , S. Raja ${ }^{a}$, D. Dwarakanathan ${ }^{\mathrm{a}}$, and Amirtham Rajagopal ${ }^{\mathrm{b}}$ \\ ${ }^{a}$ Structural Technologies Division, National Aerospace Laboratories, Bangalore, India; ${ }^{b}$ Department of Civil Engineering, Indian Institute of Technology \\ Hyderabad, Hyderabad, India
}

\begin{abstract}
In the present work, the numerical assessment of vibroacoustic (VA) performance of fiber metal laminates (FML) with mid-plane center delamination is presented. A fluid structure interaction study has been done using finite element method (FEM). Experimental validation is performed on an aluminium (AL) panel for verifying the correctness of finite element $(F E)$ idealization procedure to simulate the fluid-structure interaction. Delamination is introduced in the FE model of FML panel and VA analysis is subsequently carried out. Sound transmission loss (STL) is computed on the panel with center delamination and without delamination. The overall sound pressure level (OASPL) shows that the presence of delamination ( $40 \%$ in total area) in FML has not changed the total energy of the transmitted sound when compared to aluminium and composites. However, in the narrow frequency bands $(150-200 \mathrm{~Hz}, 200-250 \mathrm{~Hz})$, the sound transmission nature has been significantly affected due to local delamination modes participating in the fluid-structure interaction process.
\end{abstract}

\section{ARTICLE HISTORY}

Received 7 January 2015

Accepted 12 August 2015

\section{KEYWORDS}

fiber metal laminate (FML); vibroacoustic (VA); delamination; fluid-structure interaction; sound pressure level (SPL); sound transmission loss (STL); overall sound pressure level (OASPL)

\section{Introduction}

Fiber metal laminates (FMLs) are hybrid materials composed of fibrous composites (GFRP) together with alternate metalic (aluminium) layers. FMLs have found large application in aircraft structures, namely, fuselage skin, cargo bay, floor board, among others. Assessment of FML properties, especially fatigue characteristics, fire resistance, and damage tolerance has become a very important research area for its qualification as aircraft materials and there have been a considerable amount of studies reported in this direction [1]. FML panels are fabricated by stacking the laminae of aluminium (AL) and glass fiber reinforced plastic. Occurrence of delamination in these panels is possible either during the manufacturing process or under operational loadings; therefore, numerical assessment of delamination in FML is of importance and has been extensively studied $[2,3]$. The effects of delamination length and orientation angle on the natural frequency of symmetric composite beams are investigated, analytically and numerically. It has been found that when delamination length increases, frequencies decrease and are subject to change due to orientation angle, shape, and location [4-6]. Various analytical models and numerical analyses for the free vibration of delaminated composites are reviewed $[7,8]$.

Theoretical and experimental analysis of the influence of debonding on the flexural stiffness and natural frequency is analyzed [9]. Observations are made on the effects of delamination size and its location around the cutout on the natural frequency of a thick square laminate; a substantial decrease in natural frequencies is observed [10]. The possibility of delamination detection using nonlinear interaction in the delaminated region is explored [11]. In functionally graded beams with a single delamination, the natural frequencies are affected when the beam has longer delamination [12]. Vibrothermography experiments have been carried out to detect the delamination type of defects to assess the impact severity in FML [13]. Delamination in FML and its influence on the buckling failure has been investigated numerically as a specific failure mode [14].

Vibroacoustic (VA) coupling has become a critical parameter with the introduction of new lightweight materials, such as composites. Many works are presented on the vibroacoustic front where acoustic response of panels with attached passive sound insulation materials has been discussed [15]. A coupled structural-acoustic analysis procedure for industrial application has been developed in [16]. Transmission loss of multilayer composite panels is predicted under satistical energy analysis (SEA) framework using the wave theory [17]. Vibroacoustic interactions between the structure and acoustic media are considered in calculating the sound transmission loss for a long cylindrical stiffened shell, subjected to a plane wave incidence [18]. Other notable studies can be seen in this promising area, addressing the dynamic instability of delaminated composite plates $[19,20]$, delamination growth in FML [21-23] and VA analysis of multi-layer composite panels [24], characterization of cellular material structure [25], and VA behavior in biosourced composites [26].

Sound transmission loss (STL) is one of the most important measurements in determining a material's effectiveness at isolating sound. There have been very limited studies reported for evaluating the VA characteristics of FML in terms of sound transmission loss and the distributed sound pressure level (SPL).

CONTACT Amirtham Rajagopal @rajagopal@iith.ac.in EDepartment of Civil Engineering, Indian Institute of Technology Hyderabad, Kandi(V), Sangareddy(M), Medak District 502285, Telangana, India.

Color versions of one or more of the figures in the article can be found online at www.tandfonline.com/umcm.

(c) 2016 Taylor \& Francis Group, LLC 
The Federation of Aviation Regulation (FAR) authority has laid stringent norms on the noise levels inside the fuselage cabin [27]. The recent works on the damage tolerant capability of FML to enhance its structural performance have not considered the VA characteristics [1-3, 28, 29].

Making the appropriate choice of materials for aircraft structures from an acoustic point of view has been imperative. There are limited studies made on evaluation of FML panel's response under acoustic loadings and its potential in sound transmission $[30,31]$. As the overhead of experimental trials is usually very high and time consuming, it is apparent that computational modeling of the behavior of FML to acoustic loads would be of enormous interest and benefit to the aerospace industries and this forms the primary focus of this work.

In the present work we are evaluating the VA performance of FML with aluminium and composite, in the presence of delamination. For this purpose, the work is carried out in three stages. In the first stage, the VA procedure is validated using FEM, where a numerical model of the impedance tube with aluminium panel placed in between the sender and receiver chamber are modeled and the procedure is validated with the literaure [16]. In the second stage, a VA test facility is built to measure the STL of the aluminium panel and the experimental results are compared with the finite element (FE) analysis. In the third stage, a delamination modeling procedure in composite is validated with the literature [19]. Based on these validated procedures the delaminations are introduced in composites, two-layered AL and FML and their VA performance in terms of STL, SPL, and overall sound pressure level (OASPL) of different frequency bands of interest within $0-250 \mathrm{~Hz}$ is evaluated using the digital impedance tube. The article is organized as follows. Section 2 briefly discusses the governing equations of fluid structure coupling. Section 3 explains the numerical modeling of impedance tube and the experimental measure of STL, and also highlights the delamination modeling procedure in panels. Section 4 deals with the results and discussion in the presence of delamination and its effect on VA performance of FML/composite and AL panels individually. Section 5 presents the observations on the results obtained, and finally, Section 6 gives the conclusion to the work carried out.

\section{Vibroacoustic modeling of FML in ANSYS}

In VA analysis, the governing equations of structure and fluid are used, along with the required coupling load vectors. In the formulation of fluid-structure interaction problems, the structural system is modeled using the Raleigh-Ritz approach and the fluid is idealized with Galerkins's method.

The acoustic wave equation is given by:

$$
\frac{1}{c^{2}} \frac{\partial^{2} P}{\partial t^{2}}-\{L\}^{T}(\{L\} P)=0,
$$

where $c$ is speed of sound in fluid medium in time $t, P$ is the acoustic pressure, and $L$ is the matrix operator (gradient and divergence).

The Galerkin-based FE procedure is applied to form the element matrices by discretizing the wave equation (Eq. 1). In a fluid-structure interaction problem, the fluid pressure load acting at the interface is added to the dynamic equilibrium equation. The structural equation in its final form can be presented as:

$$
\left[M_{e}\right]\left\{\ddot{u}_{e}\right\}+\left[C_{e}\right]\left\{\dot{u}_{e}\right\}+\left[K_{e}\right]\left\{u_{e}\right\}=\left\{F_{e}\right\}+\left\{F_{e}^{p r}\right\},
$$

where $M_{e}, C_{e}$, and $K_{e}$ are the mass, damping, and stiffness matrices, respectively; $\ddot{u}_{e}, \dot{u}_{e}$, and $u_{e}$ are the acceleration, velocity, and displacement vectors, respectively. $F_{e}$ is the applied load vector and $F_{e}^{p r}$ is the fluid pressure load vector.

The complete finite element equations for the fluid-structure interaction problem are given in matrix form as:

$$
\begin{aligned}
& {\left[\begin{array}{cc}
{\left[M_{e}\right]} & {[0]} \\
{\left[M^{f s}\right]} & {\left[M_{e}^{p}\right]}
\end{array}\right]\left\{\begin{array}{l}
\left\{\ddot{u}_{e}\right\} \\
\left\{\ddot{P}_{e}\right\}
\end{array}\right\}+\left[\begin{array}{c}
{\left[C_{e}\right][0]} \\
{[0]\left[C_{e}^{p}\right]}
\end{array}\right]\left\{\begin{array}{c}
\left\{\dot{u}_{e}\right\} \\
\left\{\dot{P}_{e}\right\}
\end{array}\right\}} \\
& +\left[\begin{array}{cc}
{\left[K_{e}\right]\left[K^{f s}\right]} \\
{[0]} & {\left[K_{e}^{p}\right]}
\end{array}\right]\left\{\begin{array}{c}
\left\{u_{e}\right\} \\
\left\{P_{e}\right\}
\end{array}\right\}=\left\{\begin{array}{c}
\left\{F_{e}\right\} \\
\{0\}
\end{array}\right\}
\end{aligned}
$$

where $\left[M^{f s}\right]=\rho_{0}\left[R_{e}\right]^{T}$, is the fluid mass matrix and $\left[K^{f s}\right]=$ $-\left[R_{e}\right]$ is the fluid stiffness matrix.

In fluid-structure interaction analysis, the acoustic fluid element will generate all of the submatrices with a superscript $p$ in addition to the coupling submatrices $\rho_{0}\left[R_{e}\right]^{T}$ and $\left[R_{e}\right]$. Submatrices without a superscript will be generated by the compatible structural element used in the model.

Coupled structural acoustic analysis is carried out using shell and solid elements in ANSYS, a general purpose finite element software. Two layers of shell elements are modeled between the source and receiver cavities and the appropriate Degrees of Freedoms (DOFs) are accordingly coupled. The upstream and downstream acoustic cavities are modeled using a FLUID30 element and the structure is modeled by a SHELL63 element. The interface between the upstream and downstream sections does not share common nodes and they are structurally and acoustically isolated. Anechoic termination is applied at both the ends of the numerical impedance tube. The upstream and downstream panels are further connected using coupling equations. A harmonic analysis has been conducted using the frontal solver. The fluid elements from acoustic cavity are selected and then the sound pressure level is subsequently plotted.

\subsection{Modeling FML with delamination for VA characterization}

Delamination may be initiated in FML, when FML is loaded along its in-plane direction; particularly if the interface layer (adhesive) between aluminium and bridging prepreg lamina is loaded considerably. For higher load levels debonding sets in; therefore, the aluminium layer and prepreg are gradually getting separated, resulting in delamination. In FML, interlaminar delamination might occur at any interface, i.e., at the interface between two glass/epoxy layers or between aluminium and glass/epoxy (refer to Figure 1). Experimental observations have shown that the delamination may grow at the resin-rich layer between the two structural layers. It's initiation, however, might be due to matrix failure inside the glass/epoxy layer. When sound is transmitted through these delaminated panels, there will be a considerable amount of change expected in the STL, 


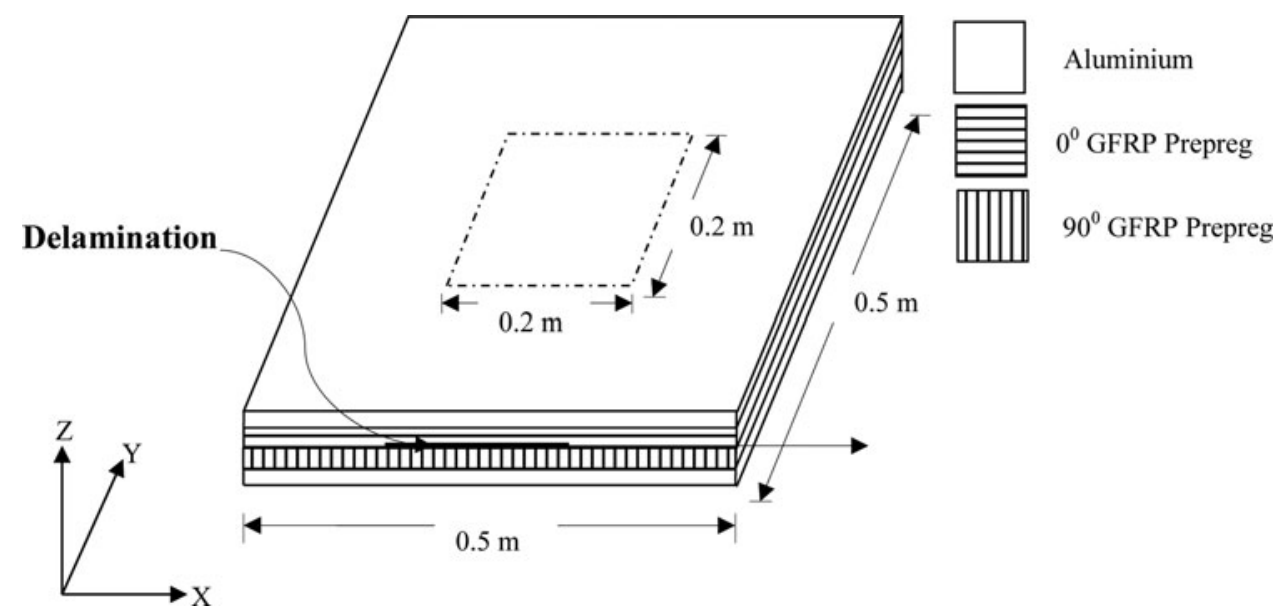

Figure 1. Fiber metal laminate with delamination.

Table 1a. Material properties used in the analysis for case studies.

\begin{tabular}{lccc}
\hline & $\begin{array}{c}\text { Aluminium } \\
\text { (for FML only) [3] }\end{array}$ & $\begin{array}{c}\text { Prepreg } \\
\text { (GFRP for FML only) [3] }\end{array}$ & CFRP-UDC \\
\hline $\mathrm{E}_{1}(\mathrm{GPa})$ & 72.4 & 48.9 & 150 \\
$\mathrm{E}_{2}(\mathrm{GPa})$ & 72.4 & 5.5 & 9.0 \\
$\mathrm{G}_{12}(\mathrm{GPa})$ & 27.6 & 5.55 & 4.0 \\
$v_{12}$ & 0.33 & 0.33 & 0.35 \\
$\rho\left(\mathrm{kg} / \mathrm{m}^{3}\right)$ & 2780 & 2471 & 1600 \\
\hline
\end{tabular}

Table 1b. Thickness, orientation, and stacking sequence used in the case studies.

\begin{tabular}{lccc}
\hline & $\begin{array}{c}\text { Panel thickness } \\
(\mathrm{mm})\end{array}$ & $\begin{array}{c}\text { Ply thickness } \\
(\mathrm{mm})\end{array}$ & Orientation \\
\hline Aluminium & 1.5 & 0.75 & {$[0 / 0]_{T}$} \\
Composite & 1.5 & 0.375 & {$[0 / 90 / 90 / 0]_{T}$} \\
FML [AL/Prepreg/AL] & 1.5 & $0.5 / 0.25 / 0.25 / 0.5$ & {$[0 / 0 / 90 / 0]_{T}$} \\
\hline
\end{tabular}

compared to panels without delaminations. To assess the VA performance, delaminations are thus introduced between GFRP prepregs and aluminium sheets of FML at the mid plane in the center of the laminate. The material data and laminate details used in the analysis are presented in Tables 1a and $1 \mathrm{~b}$. The finite element analysis is carried out to verify the change in STL due to this mid-plane delamination ( $40 \%$ in total area). Figure 1 explains the location of the simulated delamination in the FML.

\subsection{Validation of delamination procedure}

To establish the correctness of the finite element procedure for modeling delamination, a validation problem is chosen from the literature. For this purpose a composite beam is modeled in ANSYS using a layered solid element. The cantilevered beam
Table 2. Comparison of first and second frequency with and without delamination.

\begin{tabular}{lcccccc}
\hline & $\begin{array}{c}\text { Experimental } \\
\text { [19] }\end{array}$ & $\begin{array}{c}\text { FSDT } \\
{[19]}\end{array}$ & $\begin{array}{c}\text { CLT } \\
\text { [19] }\end{array}$ & $\begin{array}{c}\text { HSDT } \\
\text { [19] }\end{array}$ & $\begin{array}{c}\text { NASTRAN } \\
\text { 3D [19] }\end{array}$ & Present \\
\hline Intact (Mode 1) & 79.75 & 81.86 & 81.88 & 82.12 & 81.75 & 81.932 \\
50.8 mm (Mode 1) & 76.75 & 76.81 & 76.36 & 76.48 & 75.14 & 76.584 \\
(Delaminated) & & & & & & \\
Intact (Mode 2) & & & & 513.30 & 510.70 & 513.09 \\
50.8 mm (Mode 2) & & & & 469.02 & 478.66 & 466.35 \\
(Delaminated) & & & & & & \\
\hline
\end{tabular}

is made of T300/934 graphite/epoxy material with a $\left[0^{\circ} / 90^{\circ}\right]_{2 \mathrm{~s}}$ stacking sequence. The dimensions of the eight-layered beam are $127 \times 12.7 \times 1.016 \mathrm{~mm}^{3}$. The material properties of the lamina are: $\mathrm{E}_{11}=134 \mathrm{GPa}, \mathrm{E}_{22}=10.3 \mathrm{GPa}, \mathrm{E}_{33}=10.3 \mathrm{GPa}, v_{12}=$ $0.33, v_{23}=0.33, v_{13}=0.33, \mathrm{G}_{12}=5.0 \mathrm{GPa}, \mathrm{G}_{23}=2.0 \mathrm{GPa}$, $\mathrm{G}_{13}=5.0 \mathrm{GPa}$, and $\rho=1480 \mathrm{Kg} / \mathrm{m}^{3}$. The delamination is assumed to occur at the mid-plane of the laminate and its dimensions are $50.8 \mathrm{~mm}$ in length and $12.7 \mathrm{~mm}$ in width. Figure 2 pictorially presents the location of the delamination in the thickness direction of the laminate.

Delamination is simulated in the layered solid element model by operating the respective coupling equations in between the layers. The free vibration frequencies of the beam have been compared with the open literature. The results of the present analysis are compared very well with the reported values [19]. This validation has ensured the correctness of the delamination modeling procedure. The results are presented in Table 2. The importance of delamination in dynamics can be very well observed from the change in the dynamic behavior of cantilever beam with additional local modes introduced by delamination. These local modes, due to delamination, certainly would change the VA chracteristics of the FML/composite panels.

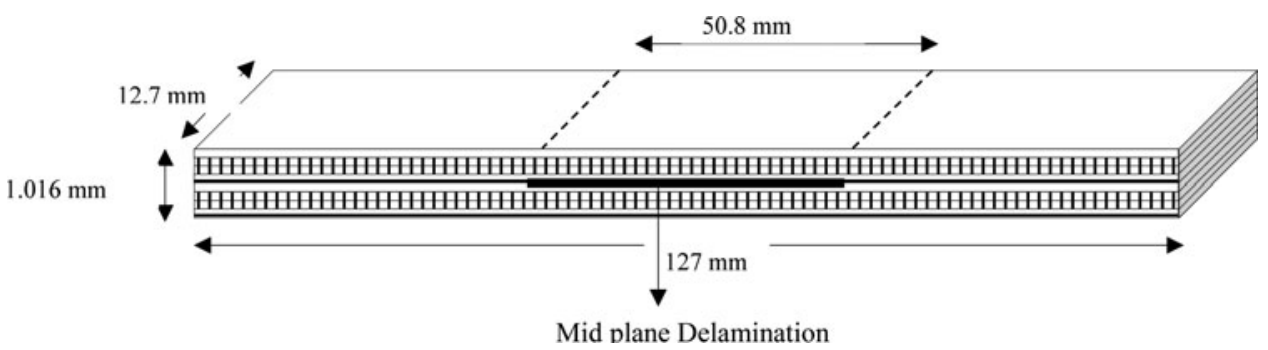

Figure 2. Delamination in composite beam [19]. 


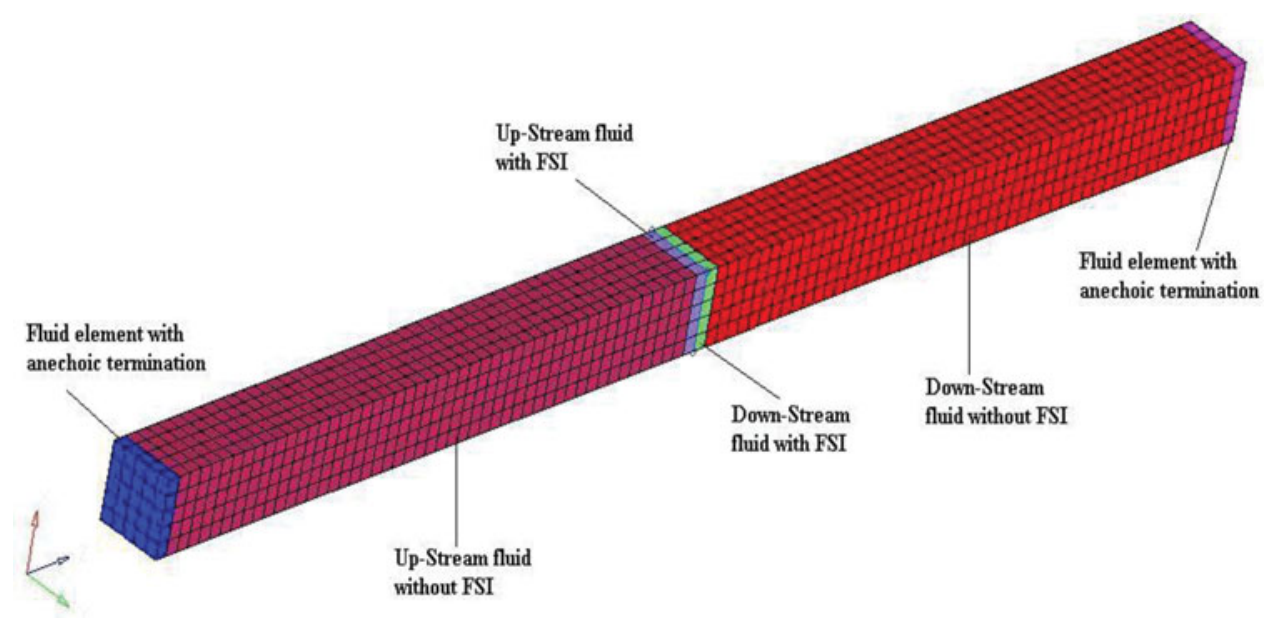

Figure 3. Finite element model of the digital impedance tube.

\section{VA simulation and experimental validations}

This section explains the finite element modeling of the impedance tube with aluminium panel and vibroacoustic measurements in a VA test facility to measure the STL and compare the test results with the finite element analysis of the VA setup. The validated delamination procedure (see Section 2.2) has been applied to aluminium, composite, and FML panels. A comparison is made in terms of VA performance parameters (STL/OASPL) among the aircraft panel structures.

\subsection{Vibroacoustic behavior of aluminium panel: Numerical studies}

The numerical study from [16] has been taken for the validation of the VA analysis procedure. To carry out VA analysis, a complete fluid-structure finite element analysis has been carried out, representing an aircraft panel placed in between senderreceiver acoustic cavities with anechoic termination boundaries (numerical model of impedance tube; refer to Figure 3). The model consists of a central AL panel and fluid (air) on either side of the panel. The AL panel is made using double layer shell elements and the fluid domain is constructed using an acoustic element. The ends of the duct are anechoically terminated. This is achieved by specifying that the elements at the end of the duct have obtained an infinite absorption through their material properties. The VA analysis has been carried out by introducing an equivalent noise source at a distance of $1.5 \mathrm{~m}$ from the aircraft panel. A low frequency, fluid structure interaction study is performed within $250 \mathrm{~Hz}$ bandwidth. The simply supported boundary condition is applied as in [16] with the same properties, loading, and finite element mesh size. The interaction of the fluid and the structure is considered at the interface, which causes the acoustic pressure to exert a force on the structure and the structural motions effectively produce the fluid load.

The results in the form of sound pressure level $(\mathrm{dB})$ are obtained after performing the vibroacoustic analysis on the aluminium panel. The obtained results are subsequently compared with the results available in the literature [16]. The results are presented in Table 3. The comparison shows that the obtained results are an exact match with the published results.
Table 3. Validation for VA simulation.

\begin{tabular}{lcccc}
\hline Result & $\begin{array}{c}\text { Max displacement, } \\
\mathrm{m}\end{array}$ & $\begin{array}{c}\text { Min SPL, } \\
\mathrm{dB}\end{array}$ & $\begin{array}{c}\text { Max SPL, } \\
\mathrm{dB}\end{array}$ & $\begin{array}{c}\text { Noise reduction across } \\
\text { the panel, } \mathrm{dB}\end{array}$ \\
\hline $\begin{array}{c}\text { Present } \\
\text { analysis } \\
{[16]}\end{array}$ & $0.741 \times 10^{-6}$ & 68.989 & 91.822 & 22.92 \\
\hline
\end{tabular}

\subsection{Vibroacoustic measurement of aluminium panel: Experimental studies}

In the next stage, the result of the finite element analysis has been compared with experimentally measured sound transmission loss. Figure 4 shows the picture of the experimental setup, where both sender and receiver chambers can be seen. Figure 5 represents an equivalent FE model of this facility. The dimensions and material are given in Table 4. Vibration testing has been performed on the aluminium panel (all edges are clamped) before exciting the specimen by acoustic loading to establish the frequency spectrum of the receiving chamber as well as the aluminium panel in order to verify any structural coupling takes place between them. When the mechanical input is applied through an impulse hammer, the source chamber is detached and also the receiver chamber is unclosed. After the vibration testing, the source chamber is attached with the receiving chamber. A band limited random noise $(0$ to $200 \mathrm{~Hz}$; $96.84 \mathrm{~dB}$ SPL measured at source) is generated and the same is supplied through a signal conditioner to the speaker. Thus, the generated low frequency noise is allowed to travel as a plane wave in the source chamber to acoustically excite the plate in order to produce its vibroacoustic modes.

Microphones (GRAS 1/2" Integrated Circuit Piezoelectric: ICP type) are placed both in source and receiving chambers to measure the sound pressure levels. It is evident from the observed results that around $6 \mathrm{~dB}$ reduction is noticed from source to receiver; which clearly shows the ability of material in radiating the sound through vibrating modes. Table 5 presents the SPL measured in the source chamber (from the panel at Mic 3; $x=300 \mathrm{~mm}, y=300 \mathrm{~mm}, z=150 \mathrm{~mm}$ ) and in the receiver (from the panel at Mic 4; $x=300 \mathrm{~mm}, y=300 \mathrm{~m}, z=150 \mathrm{~mm}$ ). A good correlation has been observed between the simulation 


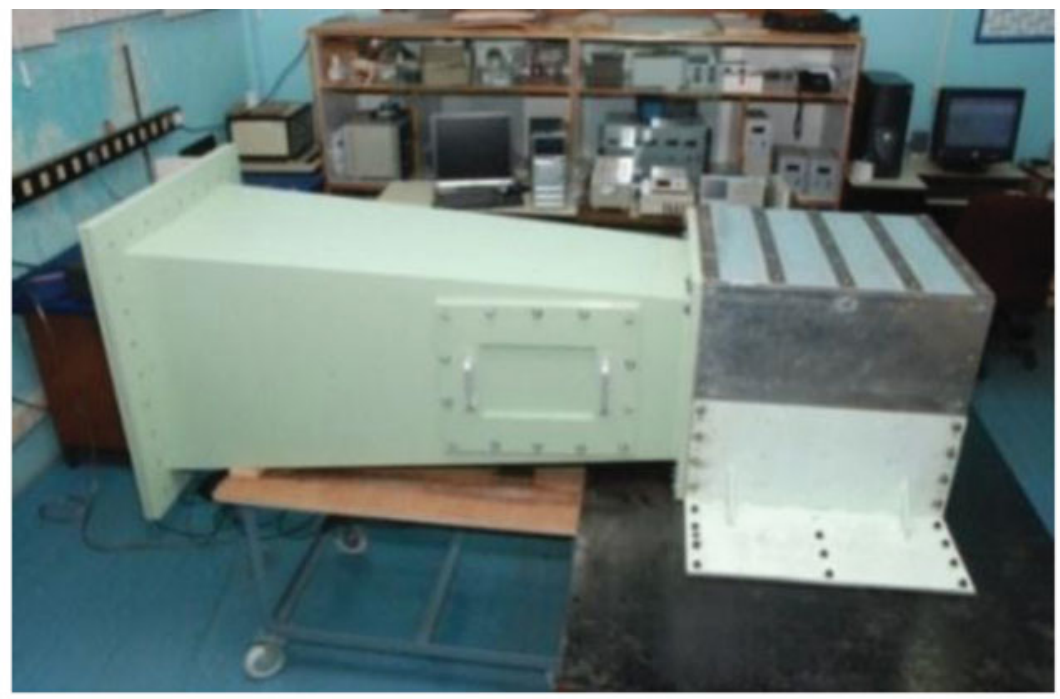

(a)

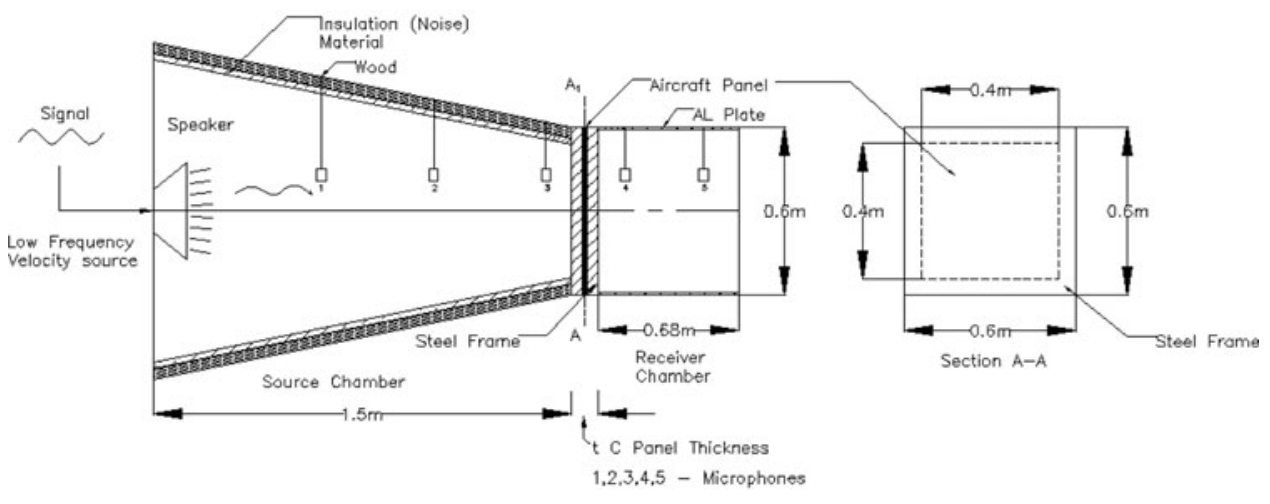

(b)

Figure 4. Vibroacoustic test facility at CSIR-NAL, India: (a) Experimental setup of VA facility and (b) schematic details of the test facility.

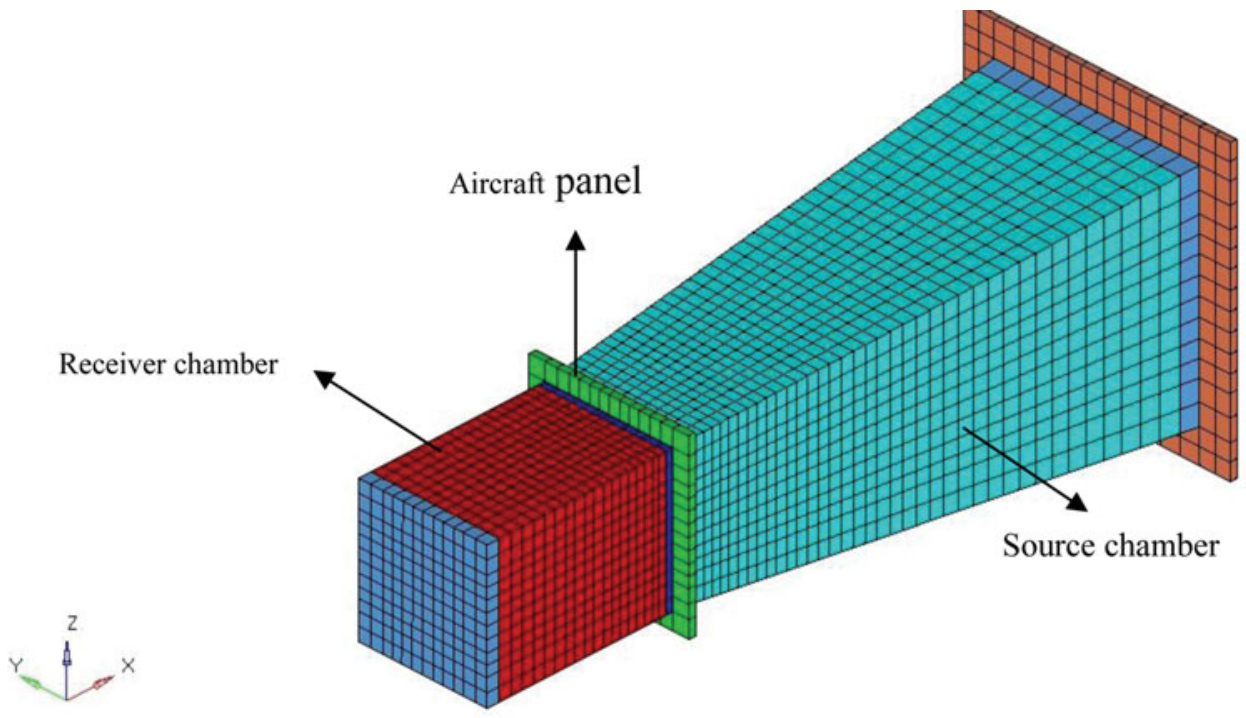

Figure 5. Finite element model of VA test facility. 
Table 4. Dimensions and material data.

\begin{tabular}{lcccc}
\hline Material & $\begin{array}{c}\text { Young's Modulus } \\
\mathrm{E}(\mathrm{GPa})\end{array}$ & $\begin{array}{c}\text { Density } \rho \\
\left(\mathrm{Kg} / \mathrm{m}^{3}\right)\end{array}$ & $\begin{array}{c}\text { Poisson's } \\
\text { ratio }\end{array}$ & $\begin{array}{c}\text { Dimensions } \\
(\mathrm{m})\end{array}$ \\
\hline Aluminium & 70 & 2700 & 0.3 & $0.5 \times 0.5 \times 0.001$ \\
\hline Material & Velocity of sound (C, $\mathrm{m} / \mathrm{s})$ & $\begin{array}{c}\text { Density } \\
\left(\rho, \mathrm{kg} / \mathrm{m}^{3}\right)\end{array}$ & $\begin{array}{c}\text { Dimensions } \\
(\mathrm{m})\end{array}$ \\
\hline Air & 340 & 1.25 & $0.4 \times 0.4 \times 0.66$ \\
\hline
\end{tabular}

Table 5. Comparison of noise reduction obtained through analysis and experiment.

\begin{tabular}{lccc}
\hline Method & $\begin{array}{c}\text { SPL at Mic 3, dB } \\
\text { (source chamber) }\end{array}$ & $\begin{array}{c}\text { SPL at Mic 4, dB } \\
\text { (receiver chamber) }\end{array}$ & $\begin{array}{c}\text { Noise reduction across } \\
\text { the panel, dB }\end{array}$ \\
\hline Experiment & 96.84 & 90.35 & 6.49 \\
Analysis & 96.81 & 90.70 & 6.11 \\
\hline
\end{tabular}

and experiment, which validates the developed numerical VA scheme in the low frequency region.

\section{Numerical analysis}

In this section the results of the sound transmission loss analysis on various panels, such as AL, composite, and FML, with and without delamination are discussed.

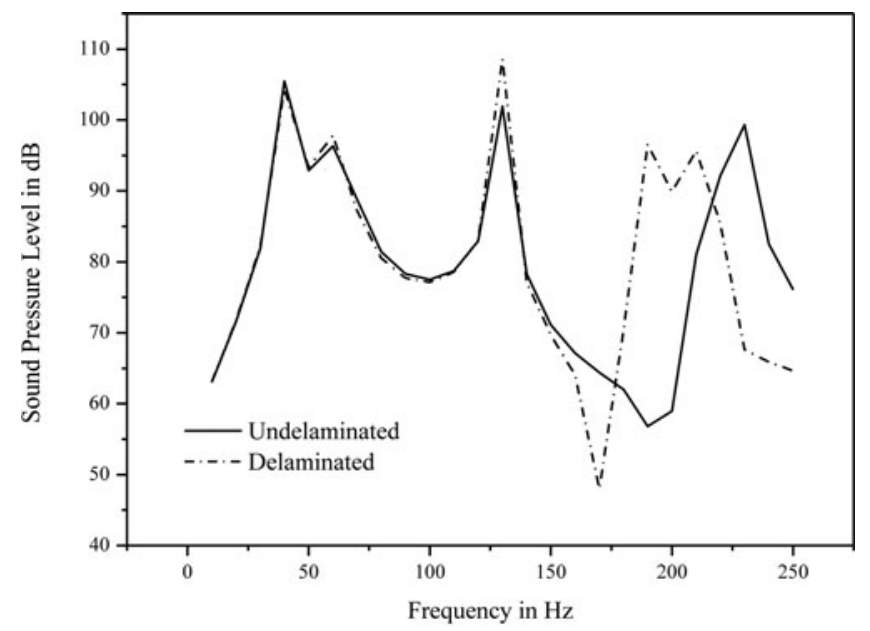

(a)

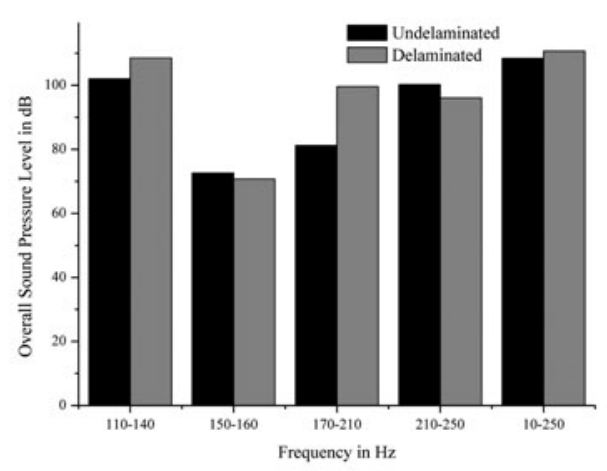

(b)

Figure 6. (a) Plot of frequency vs. sound pressure level in aluminium panel. (b) Plot of frequency vs. overall sound pressure level in aluminium panel.
Table 6. Delamination modes in panel $(<250 \mathrm{~Hz})$.

\begin{tabular}{lcc}
\hline & Mode 1 in $\mathrm{Hz}$ & Mode 2 in Hz \\
\hline Aluminium (2 layers) & 190.23 (coupled) & 215.38 \\
Composite & 157.51 & - \\
FML & 108.7 & 234.65 \\
\hline
\end{tabular}

\subsection{Delamination and its effect on vibroacoustic performance of aircraft panels}

The vibroacoustic performance and characteristics of delaminated panels (AL/composite/FML) are evaluated.

The local delamination modes depend upon the delamination size, namely, length and width (area), i.e., extent of delamination besides its locations. If delamination occurs at a high stiffness region then it will influence the frequency of the global modes to come down because of the reduction in the bending stiffness. Therefore, in the frequency band of the vibratory system these local delamination modes may be occurring depending upon the size, location, and shape of the debonding/delamination.

The present investigation has examined two such local delamination modes, which occurred in between the elastic

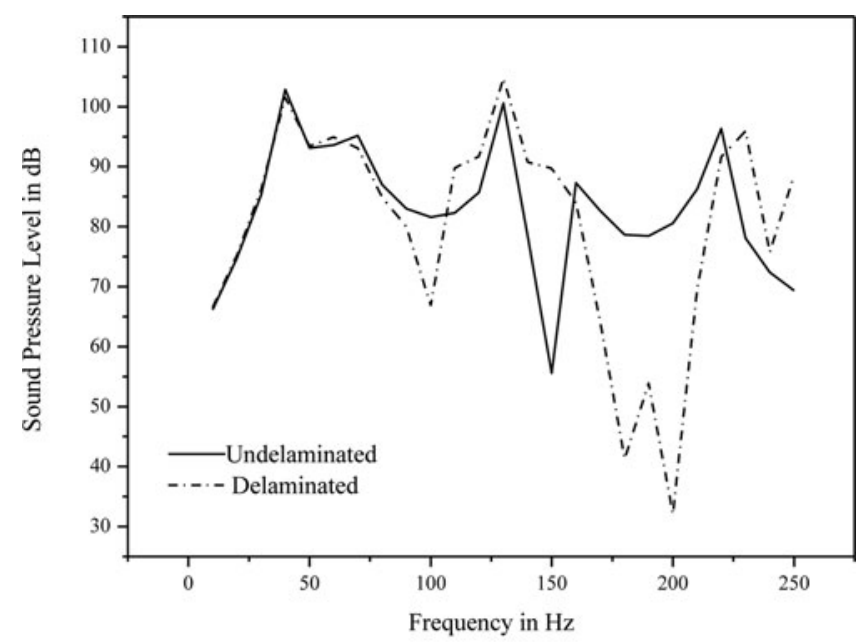

(a)

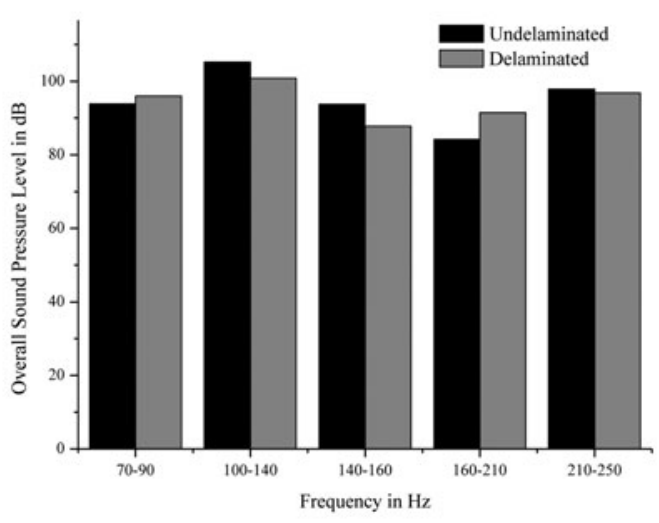

(b)

Figure 7. (a) Plot of frequency vs. SPL in composite panel with and without delamination. (b) Plot of frequency vs. OASPL in composite panel with and without delamination. 


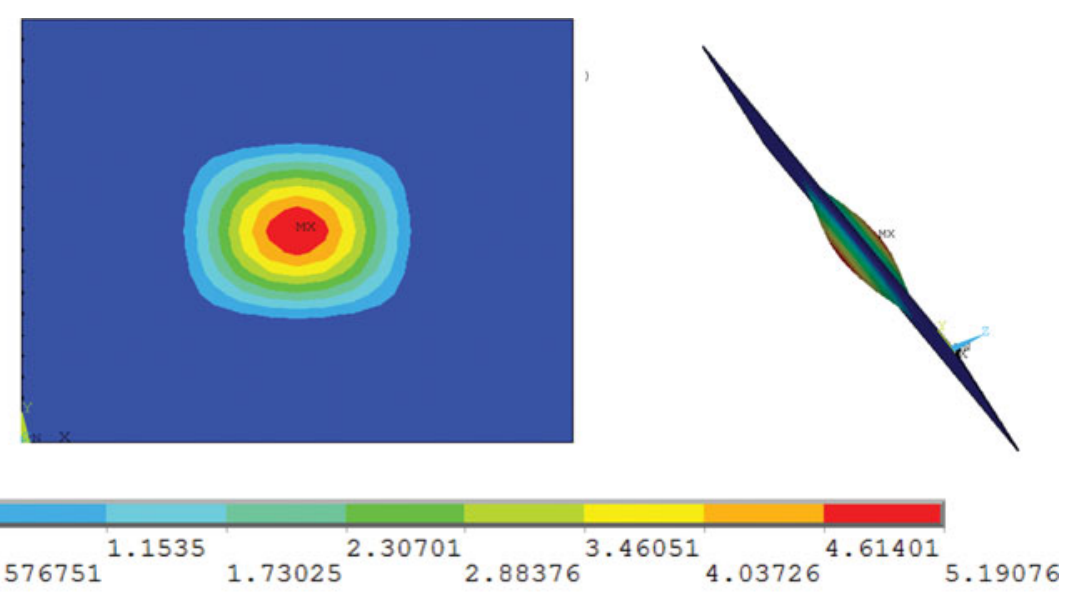

(a)

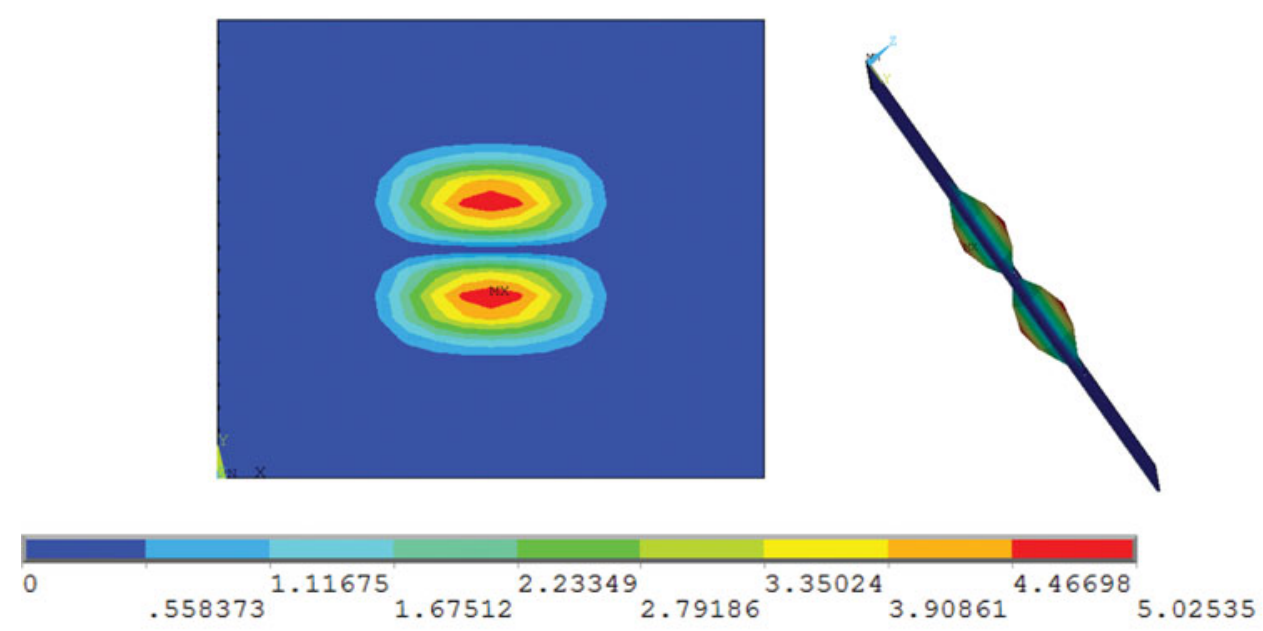

(b)

Figure 8. Delamination modes in FML: (a) Local 1st breathing mode in panel with center delamination; (b) Local 2nd breathing mode in panel with center delamination.

modes. In the free vibration analysis, all of the elastic modes within $<250 \mathrm{~Hz}$ are obtained (for FML: 12 modes; for composites: 8 modes). And these modes are subsequently used in the fluid structure interaction (FSI) analysis using the numerical impedance tube model. The presence of delamination has introduced additionally two modes in the considered frequency band. The pressure load as a sine sweep with $1 \mathrm{~Hz}$ resolution is applied to the panel and the FSI responses are obtained. Therefore, it is to be noted that the VA response calculation is performed at every $1 \mathrm{~Hz}$. Further, the OASPL is computed with a narrow band around the coupled elastic modes with fluid, including the delamination mode(s). Also, it can be seen that those frequencies, which are not influenced by fluid in the presence of VA source, do not participate or transmit the noise effectively from the source to receiver chamber (refer to SPL plots). Thus, the peaks that appeared in the SPL plots have been considered as critical frequencies in VA response analysis.

Due to delamination, some of the elastic modes' frequencies are reduced and few of them are close to the local delamination modes. Thus, a narrow band analysis is considered while computing the OASPL covering the critical modes, as well as modes influenced by delamination. The FSI analysis is carried out only up to $250 \mathrm{~Hz}$. The panel is modeled inside the impedance tube finite element model (see Figure 3), where the STL of an aluminium panel has been already validated. The present study is conducted on three panels: the first one is an aluminium panel made of two layers with a void introduced in between them; the second panel is a symmetric cross ply composite laminate; and the third panel is fiber metal laminate. The study has focused on delaminated and undelaminated panels modeling, followed by VA analysis to evaluate the influence of delamination on sound transmission loss in isotropic, composite, and fiber metal laminate to a near field acoustic load $(94 \mathrm{~dB}, 0-250 \mathrm{~Hz})$. Table 6 presents the frequencies of the delaminated modes of $\mathrm{AL}$, composites, and FML.

\subsection{Sound transmission loss on AL panel with void}

The aluminium panel is modeled with $1.5-\mathrm{mm}$ thickness. Two layers, each having $0.75-\mathrm{mm}$ thickness, are assumed to be attached and the constraint equation between these layers is applied to simulate them as a single panel. To examine the effect of void or debonding between the panels on the VA performance, a void of $40 \%$ is introduced in the central region. A 


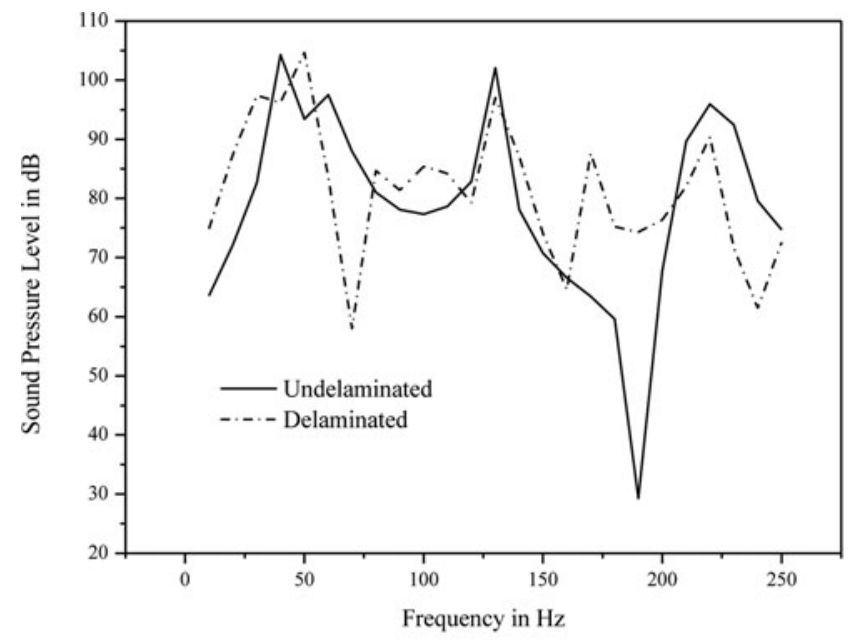

(a)

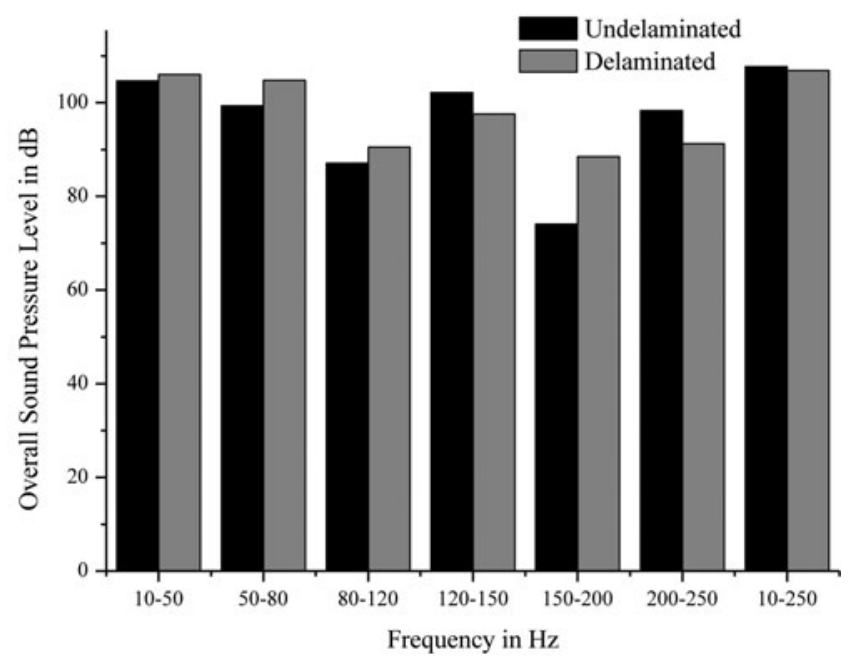

(b)

Figure 9. (a) Plot of frequency vs. sound pressure level in FML panel with and without delamination. (b) Plot of frequency vs. overall sound pressure level in FML panel with and without delamination.

moderate change in the STL values are noticed when there is a void in the AL panel. The STL and the OASPL throughout the frequency band of $0 \mathrm{~Hz}$ to $250 \mathrm{~Hz}$ are plotted in Figures $6 \mathrm{a}$ and $6 \mathrm{~b}$. From the SPL plot, it can be seen that there is no drastic change noticed in the SPL level up to $125 \mathrm{~Hz}$; but after that a significant change has taken place. The OASPL has confirmed this fact, which is observed in the band of 170 to $210 \mathrm{~Hz}$ (refer to Figure 6b). It is interesting to note that the local modes introduced due to void, actually appear in the frequency band of 170 to $210 \mathrm{~Hz}$.

Therfore, it can be understood that the noise radiation is influenced by debonding or delamination; in particular, the local delamination modes radiate the sound considerably.

\subsection{Effect of delamination on STL in composite panel}

A symmetric GFRP laminate with a layup sequence of $[0 / 90 / 90 / 0]_{T}$ and ply thickness $0.375 \mathrm{~mm}$ is considered. The material data in Table 1 is used. The same modeling scheme is

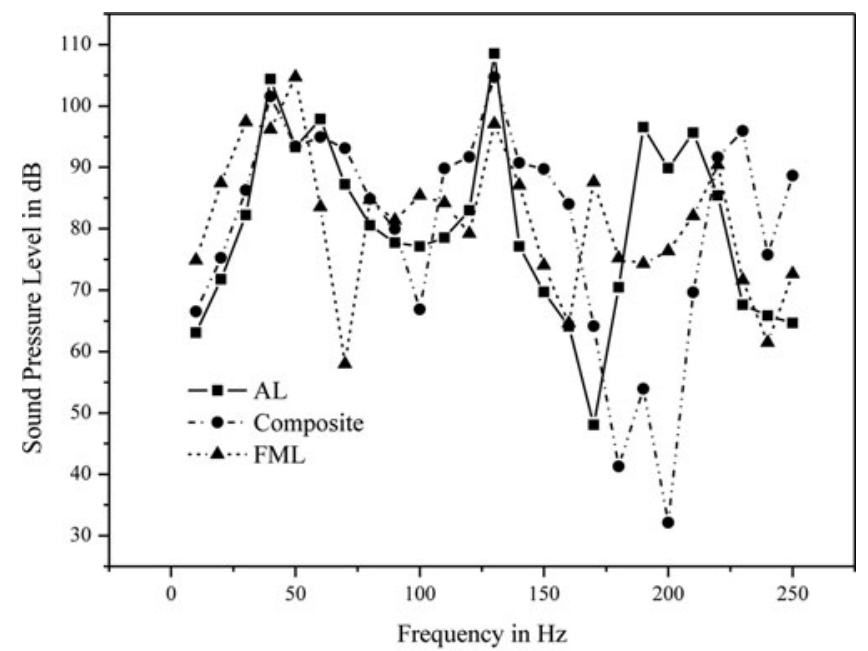

(a)

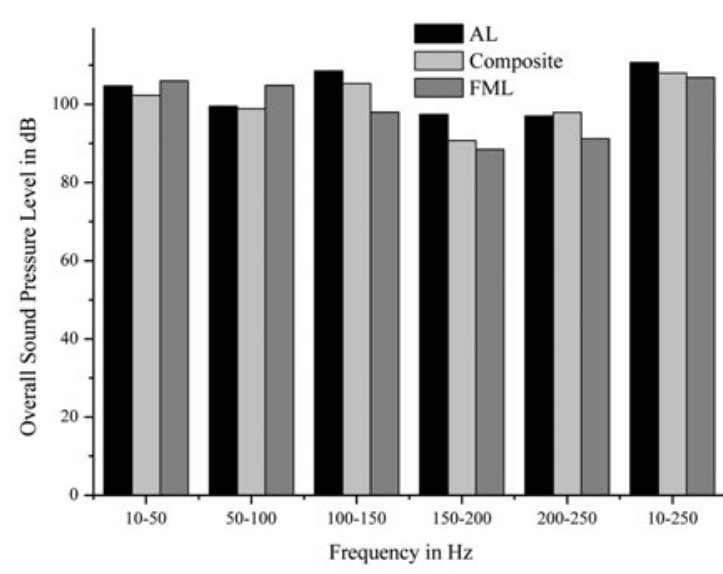

(b)

Figure 10. (a) Plot of frequency vs. sound pressure level of delaminated FML compared with delaminated AL and composite panel. (b) Plot of frequency vs. overall sound pressure level of delaminated FML compared with delaminated AL and composite panel.

adopted as in the case of AL panel and a mid-plane delamination is introduced in the laminate. VA results are presented in Figures $7 \mathrm{a}$ and $7 \mathrm{~b}$, which shows a considerable change in the STL between 150 to $210 \mathrm{~Hz}$ due to the presence of delamination mode $(157 \mathrm{~Hz})$. However, the OASPL has indicated only a moderate change in the overall band of 0 to $250 \mathrm{~Hz}$ other than 140 to $160 \mathrm{~Hz}$ band, where the influence of delamination mode $(157 \mathrm{~Hz})$ is noticed. Therfore, it is obivious that the delamination mode alters the SPL distribution.

\subsection{Effect of delamination on STL in FML}

The FML panel is made up of alternate layers of aluminium (two layers, thickness of $0.5 \mathrm{~mm}$ ) and GFRP prepreg (two layers, ply thickness of $0.25 \mathrm{~mm}$ ). To examine the effect of delamination between the layers of AL and GFRP on the VA performance, it is introduced in the central interface region of the FML panel. Figures $8 \mathrm{a}$ and $8 \mathrm{~b}$ show the two local delamination modes $(108.7 \mathrm{~Hz}$ and $234.65 \mathrm{~Hz})$ that are seen in the frequency band of 0 to $250 \mathrm{~Hz}$. The STL results are presented in Figures 9a and 


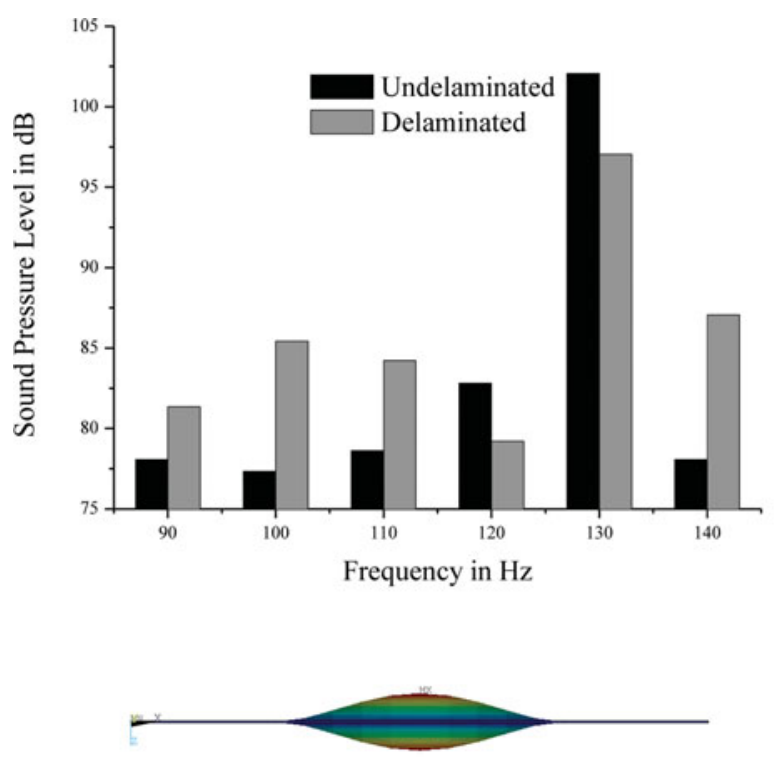

(a)
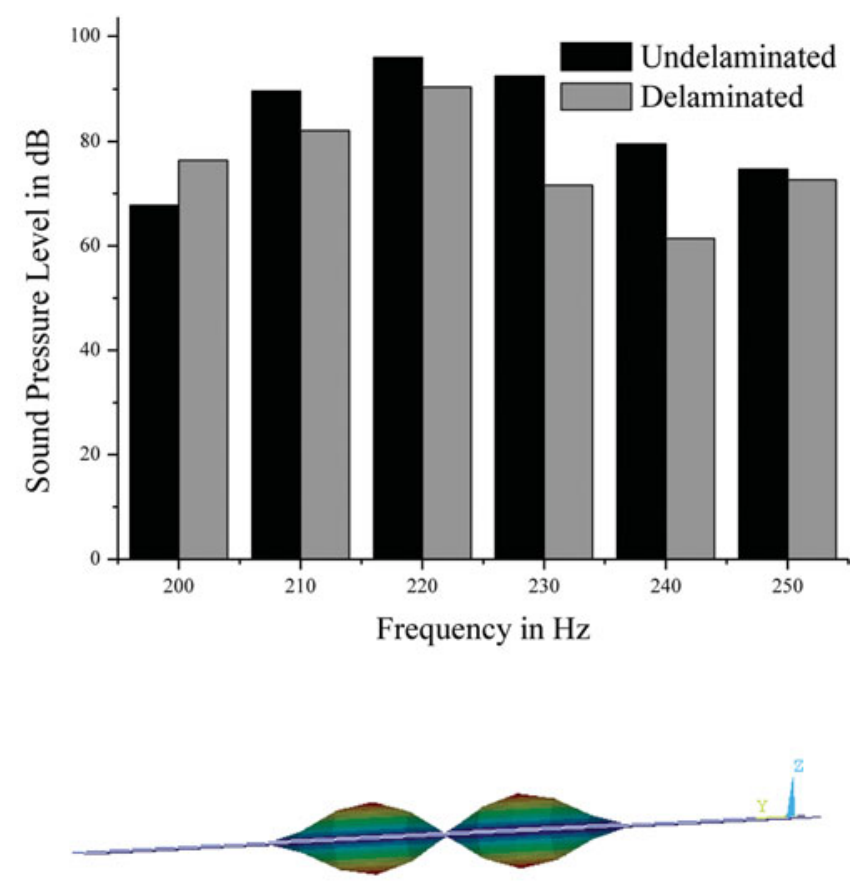

(b)

Figure 11. SPL comparison of 1st and 2nd delamination modes: (a) Symmetric breathing mode and (b) antisymmetric breathing mode.

9b. The SPL plot indicates the change in STL due to delamination in the frequency scale. The OASPL shows that the presence of delamination in FML has not changed the total energy of the transmitted sound; however, in the narrow frequency bands $(150-200 \mathrm{~Hz}, 200-250 \mathrm{~Hz})$ the sound transmission nature has been significantly modified. Further, it can be seen that the noise radiation pattern of the local delamination modes is different. The first local delamination mode transmits more energy, with respect to the undelaminate case.
Figures $10 \mathrm{a}$ and $10 \mathrm{~b}$ present the overall scenario of VA characteristics of isotropic, composite, and FML panels in terms of STL and OASPL. The VA performance of FML has been observed to be good in comparison to aluminium and composite laminate.

\section{Results and discussion}

The following major observations are made from the above numerical studies:

- The numerical impedance model has been found to be suitable to simulate the VA behavior of panels made of a different class of materials.

- The influence of low frequency structure borne noise on vibrating panels has been studied to estimate the sound transmission loss and very useful engineering data, namely, SPL and OASPL of different aircraft quality materials is generated.

- Three types of aircraft panels, namely, aluminium, composite laminate, and hybrid laminate (FML) are examined for their STL performance, where the hybrid laminate FML is found to be efficient in filtering the transmitting noise.

- The presence of delamination in laminated/FML structures has affected the STL performance. These local delamination modes influence the transmitted noise being distributed with nearby global modes around its local frequency.

- In general, the symmetric breathing delamination mode transmits higher energy than the antisymmetric one in FML hybrid laminate (refer to Figures 11a and 11b).

\section{Conclusion}

A numerical model of an impedance tube with aluminium panel placed in between the sender and receiver chamber is made and VA procedure is validated with the literaure. A VA test facility is built to measure the STL of the aluminium panel and further experimental results are compared with the finite element analysis. A validated delamination modeling procedure is introduced in composites. The VA performance of aluminium, composite, and FML panels is evaluated in the frequency band of 0 to $250 \mathrm{~Hz}$, in terms of STL, SPL, and OASPL. In general, the FML has shown a good VA performance by relatively transmitting lower SPL. The presence of delamination modes has modified significantly the STL around its natural frequencies in a narrow bandwidth of 10 to $50 \mathrm{~Hz}$. The first delamination mode (1-1) and the second mode (1-2) have displayed a different tendency in transmitting the sound $(<250 \mathrm{~Hz})$. Therefore, it is understood that the presence of damage and its dynamics have a definite role in deciding the VA characteristics of aircraft panels subjected to low frequency structure-borne noises.

\section{Acknowledgments}

The authors wish to thank the Director, NAL, and Dr. Satish Chandra, Head, STTD, NAL for their support and encouragement. The authors would also like to acknowledge the experimental input provided by Mr. N. Chandra, Scientist, STTD, NAL. 


\section{References}

[1] F. Hashagen and D.R. Borst, Numerical assessment of delamination in fibre metal laminates, Comput. Methods Appl. Mech. Eng., vol. 185, pp. 141-159, 2000.

[2] J.L. Curiel Sosa and N. Karapurath, Delamination modelling of GLARE using the extended finite element method, Compos. Sci. Technol., vol. 72, no. 7, pp. 788-791, 2012.

[3] R. Alderliesten, Fatigue and damage tolerance of hybrid materials and structures-Some myths, facts, and fairytales. In: Bridging the Gap between Theory and Operational Practice, Springer, Rotterdam, the Netherlands, pp. 1245-1261, 2009.

[4] H. Çalliolu and G. Atlihan, Vibration analysis of delaminated composite beams using analytical and FEM models, Indian J. Eng. Mater. Sci., vol. 18, no. 1, pp. 7-14, 2011.

[5] T. Ercopur and B.G. Kiral, Investigation of free vibration response of E-glass/epoxy delaminated composite plates, Adv. Compos. Lett., vol. 21, no. 1, pp. 5-15, 2012.

[6] J. Yang and Y. Fu, Analysis of dynamic stability for composite laminated cylindrical shells with delaminations. Compos. Struct., vol. 78, no. 3, pp. 309-315, 2007.

[7] C.N. Della and D. Shu, Vibration of delaminated composite laminates: A review. Appl. Mech. Rev., vol. 60, no. 1-6, pp. 1-20, 2007.

[8] M.H. Kargarnovin, M.T. Ahmadian, R.A. Jafari-Talookolaei, and M. Abedi, Semi-analytical solution for the free vibration analysis of generally laminated composite Timoshenko beams with single delamination, Composites Part B, vol. 45, no. 1, pp. 587-600, 2013.

[9] H.Y. Kim and W. Hwang, Effect of debonding on natural frequencies and frequency response functions of honeycomb sandwich beams, Compos. Struct., vol. 55, no. 1, pp. 51-62, 2002.

[10] A. Kumar and R.P. Shrivastava, Free vibration of square laminates with delamination around a central cutout using HSDT, Compos. Struct., vol. 70, no. 3, pp. 317-333, 2005.

[11] I. Ullah, J.K. Sinha, and A. Pinkerton, Vibration-based delamination detection in a composite plate, Mech. Adv. Mater. Struct., vol. 20, no. 7, pp. 536-551, 2013.

[12] Y. Liu and D.W. Shu, Free vibration analysis of exponential functionally graded beams with a single delamination, Composites Part B, vol. 59, pp. 166-172, 2014.

[13] C. Ibarra-Castanedo, N.P. Avdelidis, E.G. Grinzato, P.G. Bison, S. Marinetti, C.C. Plescanu, A. Bendada, and X.P. Maldague, Delamination detection and impact damage assessment of GLARE by activethermography, Int. J. Mater. Prod. Technol., vol. 41, no. 1-4, pp. 5-16, 2011.

[14] C. Liu, P. Linde, and J. Pleitner, Numerical study on the buckling behavior of fiber-metal laminates (FML) with defects, 17th ICCM International Conference on Composite Materials, July 27-31, Edinburgh, United Kingdom, 2009.

[15] N. Atalla and D. Rhazi, Modeling the vibroacoustics response of structures with attached noise control materials, ASME International Mechanical Engineering Congress and Exposition, pp. 665671, November 11-17, Denver, CO, 2011.

[16] C. Howard, Coupled structural-acoustic analysis using ANSYS, Internal Report, Department of Mechanical Engineering, University of Adelaide, 2000. Avalable from url:http://www.mecheng.adelaide. edu.au/avc/publications/intreportabstract.php?abstract $=223$

[17] J.H. Lee and J. Kim, Sound transmission through periodically stiffened cylindrical shells, J. Sound Vib., vol. 251, no. 3, pp. 431-456, 2002.

[18] A. Mejdi and N. Atalla, Vibroacoustic analysis of laminated composite panels stiffened by complex laminated composite stiffeners, Int. J. Mech. Sci., vol. 58, no. 1, pp. 13-26, 2012.

[19] A.G. Radu and A. Chattopadhyay, Dynamic stability analysis of composite plates including delaminations using a higher order theory and transformation matrix approach, Int. J. Solids Struct., vol. 39, no. 7, pp. 1949-1965, 2002.

[20] K. Alnefaie, Finite element modeling of composite plates with internal delamination, Compos. Struct., vol. 90, pp. 21-27, 2009.

[21] L.H. Yam, Z. Wei, L. Cheng, and W.O. Wong, Numerical analysis of multi-layer composite plates with internal delamination, Compos. Struct., vol. 82, no. 7-8, pp. 627-637, 2004.

[22] S.U. Khan, R.C. Alderliesten, and R. Benedictus, Delamination growth in fibre metal laminates under variable amplitude loading, Compos. Sci. Technol., vol. 69, no. 15-16, pp. 2604-2615, 2009.

[23] S.U. Khan, R.C. Alderliesten, and R. Benedictus, Delamination in fiber metal laminates (GLARE) during fatigue crack growth under variable amplitude loading, Int. J. Fatigue, vol. 33, no. 9, pp. 1292$1303,2011$.

[24] S. Ghinet and N. Atalla, Vibro-acoustic behaviour of multi-layer orthotropic panels, J. Can. Acoust. Assoc., vol. 30, no. 3, pp. 72-73, 2002.

[25] M. Al-Zubi, E. O. Ayorinde, G. Emmanuelitus, M. Dundar, M. Warriach, and Y. Murty, Vibro-acoustic characterization and optimization of periodic cellular material structures (PCMS) for NVH applications, J. Mater. Sci. Res., vol. 2, no. 4, pp. 64-79, 2013.

[26] L. Dobircau, J. Rupert, D.L. Turner, E. Dargent, and J.M. Saiter, Vibroacoustic behaviour in biosourced composites, World Forum Adv. Mater., vol. 328, no. 1, pp. 56-63, 2013.

[27] GPO's federal digital system, electronic code of federal regulations, Title 14: Aeronautics and space, Part 36-Noise standards: Aircraft type and airworthiness certification, 2011. Available from http://www.gpo.gov/fdsys/granule/CFR-2011-title14-vol1/CFR-2011 -title14-vol1-part36

[28] R.M. Frizzell., C.T. McCarthy., and M.A. McCarthy, Simulating damage and delamination in fibre metal laminate joints using a threedimensional damage model with cohesive elements and damage regularization, Compos. Sci. Technol., vol. 71, no. 9, pp. 1225-1235, 2011.

[29] J.A. Sinke, Development of fiber metal laminates: Concurrent multiscale modeling and testing, J. Mater. Sci., vol. 41, pp. 6777-6788, 2006.

[30] F. Alijani, M. Amabili, G. Ferrari, and V. D’Alessandro, Nonlinear vibrations of laminated and sandwich rectangular plates with free edges. Part 2: Experiments and comparisons, Compos. Struct., vol. 105, no. 437-445, 2013.

[31] V. D'Alessandro, G. Petrone, F. Franco, and S. De Rosa, A review of the vibroacoustics of sandwich panels: Models and experiments, J. Sandwich Struct. Mater., vol. 15, no. 5, pp. 541-582, 2013. 